\title{
On national oncology journals in Europe
}

\author{
Jelle Stans ${ }^{1}$, Ellen Davids
}

${ }^{1}$ Institute for Globally Distributed Open Research and Education, Beringen, Belgium

Publishing in peer-reviewed journals is one of the main methods of disseminating research results to the scientific community. Like other disciplines, oncology has several international journals publishing research from authors all over the world. Examples of such journals are International Journal of Cancer and European Journal of Cancer. These journals are often linked to international organisations or societies. Other large journals, such as JAMA Oncology, are linked to a national association but have a strong international focus.

In Europe, this latter category includes journals such as the British Journal of Cancer. In addition, several smaller peer-reviewed national journals are available, such as Forum of Clinical Oncology and Nowotwory. Journal of Oncology linked to the Hellenic Society of Medical Oncology and Polish Society of Oncology respectively. Another category of journals is linked to several national or regional organisations, such as the Journal of the Balkan Union of Oncology.

Like the larger, international journals, these smaller national journals publish high-quality research for the benefit of the scientific community. There are, however, some potential differences that warrant further research. A first difference is that these journals might have a special role in disseminating research to the national healthcare professionals. This hypothesis is supported by the fact that some of these journals also publish in the local language in addition to English. This could potentially facilitate the accessibility to / and therefore the adoption of, novel techniques or knowledge by healthcare professionals. A second aspect of these journals could be that they function as a publication venue for local researchers. This is supported by a study on the Journal of the Balkan Union of Oncology, that found that $76.5 \%$ of the publications originated from authors in the Balkan region
[1]. A third potential difference is that these journals may not always be indexed by some of the major services such as Medline, Scopus and Web of Science Core Collection. They may however be indexed by local services. It has been suggested that these journals can benefit from being indexed in the larger databases [2]. A final difference is that due to the previous points, these journals have a smaller outreach than the larger international journals. This hypothesis could be tested by comparing metrics such as the impact factor between these journals and the larger ones.

In general, it is clear that national and regional oncology journals have an essential role in publishing high-quality scientific research. There is however still a lot to discover about their specific characteristics. A study shedding more light on this could provide these journals with better insights into their position in the landscape and help them with developing a strategy to advance towards the role they want to fulfil.

Conflict of interest: none declared

\section{Jelle Stans}

Institute for Globally Distributed Open Research and Education

Beringen, Belgium

e-mail:jelle.stans@igdore.org

Received: 22 Feb 2021

Accepted: 2 Mar 2021

\section{References}

1. Vuckovic-Dekic L, Gavrilovic D. Importance of being indexed in important databases--effect on the quantity of published articles in JBUON. J BUON. 2016; 21(1): 266-271, indexed in Pubmed: 27061557.

2. Vuckovic-Dekic L, Gavrilovic D. Progress of the Journal of the Balkan Union of Oncology in the second decade of its existence. J BUON. 2018; 23(5): 1266-1272, indexed in Pubmed: 30570846.

\section{How to cite:}

Stans J, Davids E. On national oncology journals in Europe. NOWOTWORY J Oncol 2021; 71: 183. 